EXTENDED REPORT

\title{
Conditioned medium from mixed retinal pigmented epithelium and Müller cell cultures reduces in vitro permeability of retinal vascular endothelial cells
}

\author{
M Tretiach, M C Madigan, M C Gillies
}

Br J Ophthalmol 2004;88:957-961. doi: 10.1136/bjo.2003.033894

See end of article for authors' affiliations

\section{Correspondence to:} M Tretiach, Save Sight Institute, GPO Box 4337, Sydney 2001, Australia; marina@eye.usyd.edu.au

Accepted

27 November 2003

\begin{abstract}
Aim: To investigate the in vitro effect of laser photocoagulation on blood-retinal barrier permeability. Methods: Retinal capillary endothelial cells were exposed to supernatants from long term co-cultured cells that were argon laser treated. Endothelial cell permeability was analysed by (1) measurement of transendothelial electrical resistance and $(2)$ equilibration of $\left[{ }^{3} \mathrm{H}\right]$ inulin and $\left[{ }^{14} \mathrm{C}\right]$ albumin across the cell monolayer.

Results: Laser photocoagulation of various retinal cells and control ECV304 cells in the lower chamber did not appreciably improve permeability of the endothelial cell monolayer compared with that of unlasered cells. However, medium that was conditioned by mixed retinal pigmented epithelium and Müller cells significantly reduced both inulin (43.2\% (SD 6.5\%) equilibration in mixed cultures v 59.8\% (SD 7.0\%) control cells, $p<0.05$ ) and albumin (15.1\% (SD 3.8\%) v $31.1 \%$ (SD 6.7\%), $p<0.05$ ) permeability of the endothelial cell monolayers. A fourfold increase in transendothelial electrical resistance was also seen.

Conclusions: These results are consistent with the hypothesis that interaction of Müller cells with retinal pigmented epithelium induced by laser treatment results in secretion of soluble factor(s), which reduces permeability of retinal vascular endothelium. Identification of these factor(s) may have implications for the clinical treatment of macular oedema secondary to diabetic retinopathy and other diseases.
\end{abstract}

$\mathrm{T}$ he blood-retinal barrier (BRB) exists at the level of the retinal capillary endothelium ("inner" BRB) and the retinal pigmented epithelium (RPE) (“outer' BRB). Macular oedema secondary to breakdown of the inner BRB is the most common cause of vision impairment in diabetic retinopathy. ${ }^{1}$ Retinal laser therapy reduces the risk of blindness in eyes with diabetic macular oedema. ${ }^{2}$ However, laser photocoagulation is generally administered late in the course of the disease when vision loss is imminent, may not always work, and is inherently destructive. Understanding how retinal laser treatment affects a leaking $\mathrm{BRB}$ is important for developing better treatments for macular oedema.

Changes in retinal morphology after laser have been well described in rats, ${ }^{3}$ rabbits, ${ }^{4}$ monkeys, ${ }^{5}$ and humans. ${ }^{67}$ Although some laser energy may directly affect the retinal vessels, it is generally accepted that the major site of absorption is the RPE and choroid. ${ }^{6}$ The laser affected areas of the photoreceptor outer segments and RPE exhibit signs of necrosis including cell disruption, vacuolisation, and condensation of cytoplasmic proteins within a few hours after treatment ${ }^{4}$ to an extent that is commensurate with the intensity of the burn. ${ }^{5}$ Within days, RPE cells migrate across Bruch's membrane to fill the lesion with subsequent scar formation. ${ }^{89}$ Müller cells and astrocytes replace the damaged outer nuclear layer of the retina, interdigitating with the migrated RPE cells. ${ }^{7}{ }^{10}$ Müller cells undergo widespread and long lasting changes after photocoagulation including increased expression of glial fibrillary acidic protein (GFAP) associated with hypertrophy, migration, and scar tissue formation. ${ }^{11}$

We propose that laser photocoagulation stimulates cells to produce soluble factor(s) that can restore a leaky BRB. In this study, we tested the hypothesis that supernatants from RPE, Müller cells, pericytes, and control ECV304 cells can reduce the in vitro permeability of a retinal capillary endothelial cell (RCEC) monolayer.

\section{MATERIALS AND METHODS}

\section{Cell isolation and culture}

A mixed cell population of postmortem activated RPE and migrating Müller cells was isolated from 24-48 hour postmortem bovine eyes using a modification of Edwards' method $^{12}$ and based upon previous observations on the characteristics of postmortem Müller cells. ${ }^{13-17}$ A coronal section of the globe was made and the cornea, lens, and vitreous tissues were removed as one piece. The retina was carefully dislodged, and the remaining traces of retinal tissue were removed from the optic nerve with a sterile scalpel blade. Two eyecups were filled with $0.25 \%$ trypsin ethylenediamine tetra-acetic acid (TE) (ThermoTrace Biosciences, Melbourne, Australia) and incubated at $37^{\circ} \mathrm{C}$ for 15 minutes. The enzyme mixture was pipetted to gently loosen adherent cells, and the eyecups containing TE were incubated for a further 15 minutes. Dissociated cells were removed and transferred into Dulbecco's modified Eagle's medium (DMEM) (ThermoTrace Biosciences) containing 20\% heat inactivated fetal bovine serum (FBS) (ThermoTrace Biosciences), $2 \mathrm{mM}$ glutamine, $100 \mathrm{IU} / \mathrm{ml}$ penicillin, and $100 \mu \mathrm{g} / \mathrm{ml}$ streptomycin (ThermoTrace Biosciences). Cells were centrifuged at $163 \mathrm{~g}$ for 6 minutes. The cells were resuspended in fresh medium and seeded into a $25 \mathrm{~cm}^{2}$ flask (Nunc A/S, Roskilde, Denmark). Eyecups were filled with fresh TE and incubated for a further 30 minutes. The product of the second eyecup digestion was centrifuged and incubated as above. The first digest of the eyecup produced a mixed population of cells, whereas the second digest

Abbreviations: BRB, blood-retinal barrier; CRALBP, cellular retinaldehyde binding protein; DMEM, Dulbecco's modified Eagle's medium; EC, endothelial cell; $F B S$, fetal bovine serum; GFAP, glial fibrillary acidic protein; MW, molecular weight; NDS, normal donkey serum; RCEC, retinal capillary endothelial cell; RPE, retinal pigmented epithelium; TE, trypsin ethylenediamine tetra-acetic acid; TEER, transendothelial electrical resistance. 
provided a high yield of RPE cells. Cells were incubated undisturbed for $1-2$ weeks at $37^{\circ} \mathrm{C}(95 \%$ relative humidity, $\left.5 \% \mathrm{CO}_{2}\right)$. At the first or second passage, cells were seeded (15000 cells per well) into the lower chamber of 24 well Costar Transwell plates (Corning Inc, Acton, MA, USA) with DMEM containing 10\% FBS. Medium was replaced 24 hours after seeding, and then twice weekly for 3 months as previously described for long term RPE cultures. ${ }^{18}$

Other cell types were cultured in 24 well plates as described above. Pericytes were isolated by enzyme digestion of bovine retinas; ${ }^{19}$ Müller cells were isolated from bovine retinas following the method of Tretiach et al, ${ }^{20}$ and bovine RCEC were isolated using an enzyme digestion technique followed by filtration to collect the microvessel fragments. ${ }^{21} \mathrm{~A}$ human bladder carcinoma derived epithelial cell line (ECV304, European Collection of Cell Cultures, Salisbury, UK) was included as an epithelial cell control. ${ }^{22}{ }^{23}$ Cultures were photographed with Kodak Ektachrome Tl60 (Kodak, Rochester, NY, USA) film using a Zeiss Telaval 31 inverted microscope (Carl Zeiss, North Ryde, NSW, Australia).

\section{Immunohistochemistry}

Cells from primary cultures were routinely immunostained with a panel of antibodies (table 1). Antibodies, except anticellular retinaldehyde binding protein (CRALBP), were visualised using either Alexa 488 or 568 conjugated secondary antibodies. For CRALBP localisation, early passage Müller cells and RPE were grown to confluence on glass coverslips, rinsed with phosphate buffered saline (PBS) ( $\mathrm{pH} 7.4$ ), fixed in ice cold methanol for 15 minutes, then rinsed in PBS. Cells were blocked in $10 \%$ normal donkey serum (NDS) and incubated overnight at $4{ }^{\circ} \mathrm{C}$ with the primary antibody or $2 \%$ NDS on the negative controls. Coverslips were rinsed in PBS, incubated in biotinylated antirabbit Ig antibody (1:50) (Amersham Pharmacia, Baulkham Hills, NSW, Australia) for 1 hour, then ExtraAvidin peroxidase (1:200) (SigmaAldrich P/L, Castle Hill, NSW, Australia) for 45 minutes. Bound antibody was detected with Vector red chromagen (Vector Laboratories, Burlingame, CA, USA). Coverslips were dehydrated through a series of alcohols and xylene and mounted with DePeX. Images were captured with Leica DC Viewer Computer Software (Version 3) (Leica Microsystems Ltd, Heerbrugg, Switzerland) using a Leitz Diaplan light microscope (Leitz Messtechnik GmbH, Wetzlar, Germany).

Table 1 Antibodies used for immunohistochemistry

\begin{tabular}{|c|c|c|c|}
\hline Antibody & Dilution & Cell type & Source \\
\hline $\begin{array}{l}\text { Polyclonal antihuman } \\
\text { ZO-1 }\end{array}$ & $1: 50$ & RCEC, RPE & $\begin{array}{l}\text { Zymed Labs Inc, } \\
\text { San Francisco, CA, } \\
\text { USA }\end{array}$ \\
\hline $\begin{array}{l}\text { Polyclonal anticow } \\
\text { CRALBP }\end{array}$ & $1: 100$ & RPE, Müller & $\begin{array}{l}\text { Prof J Saari, } \\
\text { University of } \\
\text { Washington, USA }\end{array}$ \\
\hline $\begin{array}{l}\text { Monoclonal antiswine } \\
\text { vimentin (V9) }\end{array}$ & $1: 100$ & Müller cells & $\begin{array}{l}\text { Dako, Sydney, } \\
\text { NSW, Australia }\end{array}$ \\
\hline $\begin{array}{l}\text { Polyclonal antihuman } \\
\text { vWF }\end{array}$ & $1: 50$ & RCEC & Dako, Australia \\
\hline $\begin{array}{l}\text { Monoclonal antihuman } \\
\text { aSMA (1A4) }\end{array}$ & $1: 50$ & Pericyłes & $\begin{array}{l}\text { Neomarkers, } \\
\text { Fremont, CA, USA }\end{array}$ \\
\hline Polyclonal anticow GFAP & $1: 500$ & Astrocytes & Dako, Australia \\
\hline $\begin{array}{l}\text { Monoclonal antihuman } \\
\text { NCAM }\end{array}$ & $1: 10$ & Neural cells & $\begin{array}{l}\text { Biodesign } \\
\text { International, Saco, } \\
\text { Maine, USA }\end{array}$ \\
\hline
\end{tabular}

CRALBP, cellular retinaldehyde binding protein; NCAM, neural cell adhesion molecule; GFAP, glial fibrillary acidic protein; $\alpha S M A$, alpha smooth muscle actin; vWF, von Willebrand's Factor; ZO-1, zonula occludens.

\section{Conditioned medium and argon laser studies}

Second passage RCEC ( 5000 cells per well) were seeded onto coated $0.4 \mu \mathrm{m}$ pore size polycarbonate filter $\left(0.33 \mathrm{~cm}^{2}\right)$ inserts of two chamber Transwell plates. ${ }^{21}$ Inserts were placed into wells containing the long term cultured cells (described above) to study the effects of conditioned medium on endothelial cell (EC) permeability. The conditioned medium and control cell groups (7-8 wells per group) are described in table 2. Long term cultured cells were adapted in EC medium $^{20}$ for 24 hours before co-culturing with EC. Seven days later, cells in the lower chamber were lasered as follows. Filter inserts were removed from the 24 well Transwell plate and returned to the incubator in humidified dishes. Medium was decanted from cells in the lower wells and the plates were held sideways in situ on the chin rest of a Coherent argon blue-green laser. Four wells per group received 70 shots per well with $200 \mu \mathrm{m}$ spot size, pulse duration $0.1 \mathrm{~s}, 150 \mathrm{~mW}$. The lowest dose that caused a visible reaction in the RPE monolayer on phase contrast microscopy had been established previously in dose response studies (not shown). After laser treatment, fresh medium was added to cells in the lower chamber. The Transwell filter inserts containing EC were replaced into medium that was now conditioned by the "lasered" and "unlasered" cells.

\section{Permeability studies}

Transendothelial electrical resistance (TEER) was measured using a Millipore ERS resistance meter (Millipore, NSW, Australia) as previously described. ${ }^{21}$ TEER was recorded from day 3 after the filter inserts containing EC had been added to the cell groups providing conditioned medium, and then every second day until day 7, when these groups were lasered. TEER was measured every 12 hours thereafter. We prospectively determined ${ }^{20}$ that comparisons between groups should be carried out when the control EC reached peak resistance. Presumably this situation best reflects the in vivo BRB. The mean resistance of the different groups was calculated by subtracting the average reading from the "no cell" wells (group 7) multiplied by the area of the Transwell filter $\left(0.33 \mathrm{~cm}^{2}\right)$. Results were expressed in ohms $\mathrm{cm}^{2}$. The experiment was repeated three times. Permeability of radiolabelled macromolecular tracers across the EC barrier was determined as follows. Within one hour of laser treatment, a mixture of radiolabelled tracers- $\left[\right.$ methoxy- ${ }^{3} \mathrm{H}$ ] inulin (NEN Life Science Products Inc, Boston, MA, USA) and [methyl- ${ }^{14} \mathrm{C}$ ] methylated (bovine serum) albumin (NEN Life Science Products Inc) -was added to medium in the upper Transwell chamber. The concentration of tracer was predetermined to provide a sufficient number of counts (5000-50 $000 \mathrm{dpm}$ ) in the final volume added to the luminal chamber (total count). Medium was removed from the lower chamber at 24, 36, and 48 hours. A Tricarb 2100TR Packard liquid scintillation $\beta$ counter (Packard Instrument Co, Meriden, CT, USA) using the full spectrum DPM technique

Table 2 Conditioned medium and control cell groups used in the barrier assay

\begin{tabular}{lll}
\hline $\begin{array}{l}\text { Group } \\
\text { number }\end{array}$ & Description & $\begin{array}{l}\text { Total } \\
\text { number of } \\
\text { wells }\end{array}$ \\
\hline 1 & Mixed RPE \& Müller cells & 8 \\
2 & Mixed pericyte \& Müller cells & 8 \\
3 & RPE cells alone & 8 \\
4 & Müller cells alone & 8 \\
$5^{*}$ & ECV 304 cells & 8 \\
$6^{*}$ & RCEC alone & 7 \\
$7^{*}$ & Coated filters only & 2 \\
\hline${ }^{*}$ Control groups. & \\
\hline
\end{tabular}


(Operation Manual, Packard Instrument Co) was used to calculate radioactivity of the individual radionuclides. A ratio of the radioactivity from each of the lower wells to the total count was determined for each timepoint and expressed as the percentage equilibration.

\section{Statistics}

As we anticipated that the in vitro EC barrier enhancing effect occurred after a delayed response to photocoagulation, we compared the conditioned medium groups with the control EC at the later timepoints: between 24-48 hours after lasering. Results were calculated as follows: (1) mean (standard deviation) electrical resistance $\left(\right.$ ohms $\left.\mathrm{cm}^{2}\right)$ for the TEER, and (2) equilibration of tracers was expressed as mean (SD) per cent (\%) for the permeability studies. Repeated measures ANOVA followed by linear contrast was used to analyse the data. Time was treated as the within subject factor and group as the between subject factor. The level of significance was set at $\mathrm{p}=0.05$.

\section{RESULTS}

\section{Cell morphology and immunohistochemistry}

All primary cells grew to confluence within one week after seeding into culture flasks. Cells cultured from the first digest of the eyecups contained a mixed population of two distinct cell types (fig lA). Retinal pigmented epithelium and Müller cells were identified in these cultures, where RPE displayed intense pigmentation and characteristic cobblestone morphology and Müller cells exhibited long, delicate radial fibre structures and distinctive varicosities around the cell body. Cells cultured from the second digest consisted of $>90 \%$ RPE (fig 1B) as determined with specific antibody labelling (fig 1C). Müller cells isolated from retinal tissue were identified by anti-CRALBP (fig lD) and antivimentin immunolabelling (not shown). Cultured pericytes labelled for aSMA (not shown) showed distinct actin filaments within large, amorphous cells. Contamination of primary cultures by neuronal cells and/or astrocytes was estimated to be $<1 \%$ based on immunolabelling for NCAM and GFAP (not shown).

\section{Long term cultures}

With phase microscopy, long term mixed RPE and Müller cell cultures (Pl-2) grown in 24 well plates appeared as flat, uniform sheets with foci of darkly pigmented areas (fig lE). RPE cells alone appeared to grow irregularly with areas of multilayering (fig IF). Mixed pericytes and Müller cells grew without extensive contact in the long term cultures albeit with good coverage of the dish surface (fig lG). Many pericytes became detached from the lower well surface by completion of the experiment, when the upper Transwells were removed. The predominant population remaining on the lower well surface were Müller cells. ECV304 cells remained as a stable monolayer with characteristic cobblestone morphology (fig $1 \mathrm{H}$ ) for up to 4 months in culture. Lasering of the long term cultured cells did not appear to change cell morphology dramatically.

\section{Permeability results}

Transendothelial electrical resistance of control EC reached $9.0 \Omega \mathrm{cm}^{2}$ on day 5 and remained fairly constant thereafter, peaking at $11.7 \Omega \mathrm{cm}^{2}$ on day 8 (thick line in fig $2 \mathrm{~A}$ ). By day 9, TEER of EC grown in medium conditioned by mixed RPE and Müller cell cultures (fig 2A) was fourfold that of the control EC and the other conditioned medium groups (fig 2B). Conditioned medium from mixed RPE and Müller cells that were laser treated did not significantly effect TEER of the EC barrier (not shown).
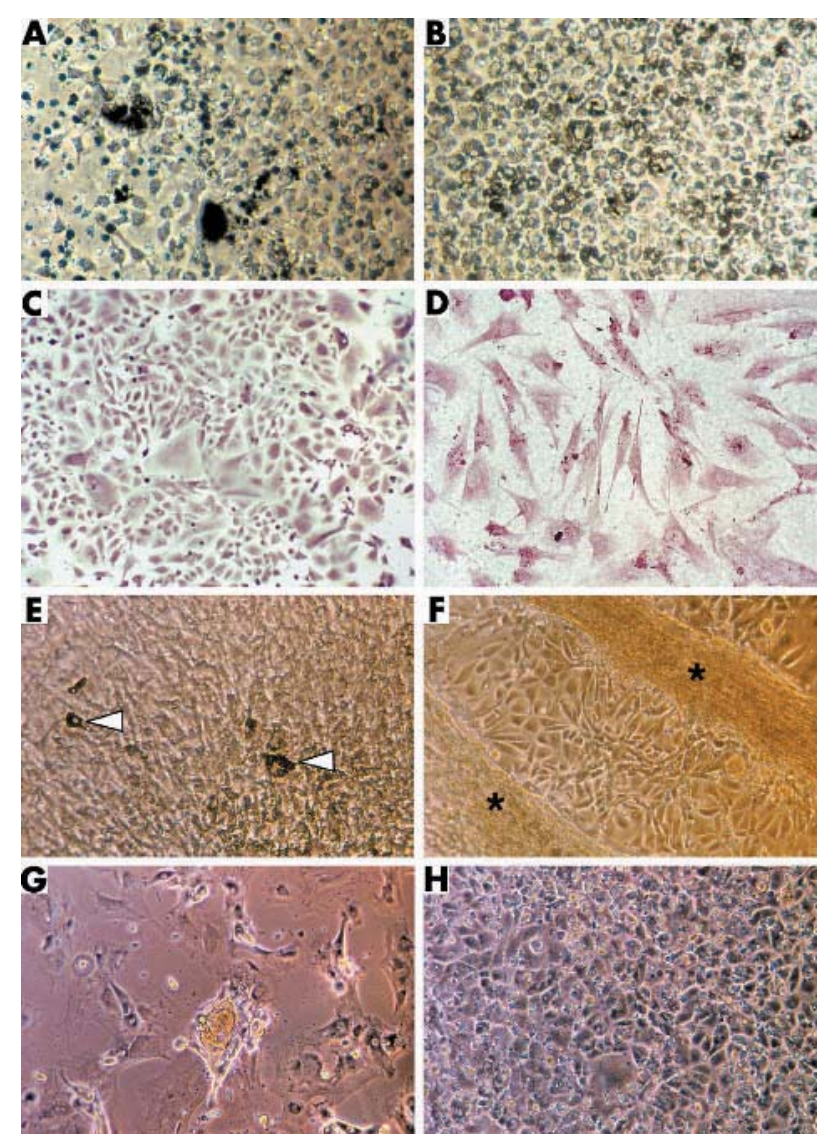

Figure 1 Phase contrast images showing PO mixed cells from first trypsin digest of the eyecups (A), and PO retinal pigmented epithelium (RPE) cells from the second trypsin digest (B) ( $\times 150$ magnification). Light micrographs of P1 RPE cells (C) $(\times 100)$ and P1 Müller cells (D) $(\times 250)$ showing immunolabelling for cellular retinaldehyde binding protein. Phase contrast images of cells before lasering, including long term mixed P1 RPE and Müller cells with focal areas of dark pigmentation (arrowheads) (E) ( $\times 130)$, long term P2 RPE cells showing areas of multilayered cells (asterisk) (F) ( $\times 100$ ), long term mixed P1 pericyte and Müller cell culture showing growth with contact inhibition $(G)(\times 100)$, and long term ECV304 cells with characteristic monolayer morphology (H) $(\times 100)$.

As there was no difference in results between the lasered and unlasered wells in each group, we combined the outputs from both groups to improve the statistical power. Groups in which there was an obvious effect on EC permeability were analysed using repeated measures ANOVA as described above. The difference between EC exposed to supernatants from the mixed RPE and Müller cell group (43.2\% (SD 6.5\%) equilibration) and control EC (59.8\% (SD 7.0\%) equilibration) was significant for inulin $(\mathrm{p}<0.05)$ (fig 2C) and albumin leakage (15.1\% (SD 3.8\%) v 31.1\% (SD 6.7\%), $\mathrm{p}<0.05$ ) (fig 2D). Conditioned medium from other groups had no discernible effect on the overlying EC.

\section{DISCUSSION}

In this study, we set out to examine whether supernatants from a variety of lasered cells could reduce the permeability of an RCEC monolayer using a two chamber in vitro assay. Although laser treatment of cells in the lower chamber did not have any effect on EC permeability, we observed that conditioned medium from mixed RPE and Müller cells significantly reduced monolayer permeability, consistent with the hypothesis that barrier enhancing factors are released from cells within the laser scar. 
A

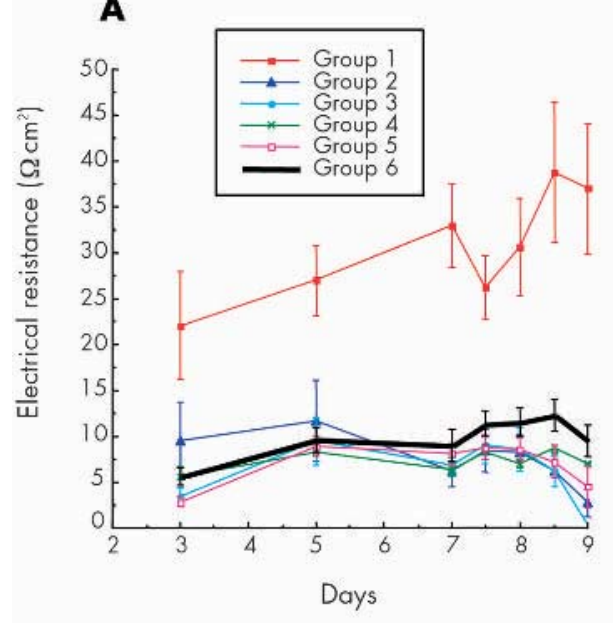

C

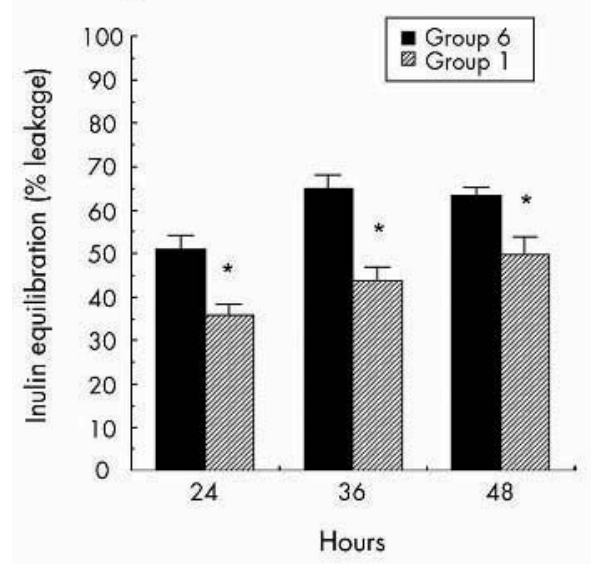

B

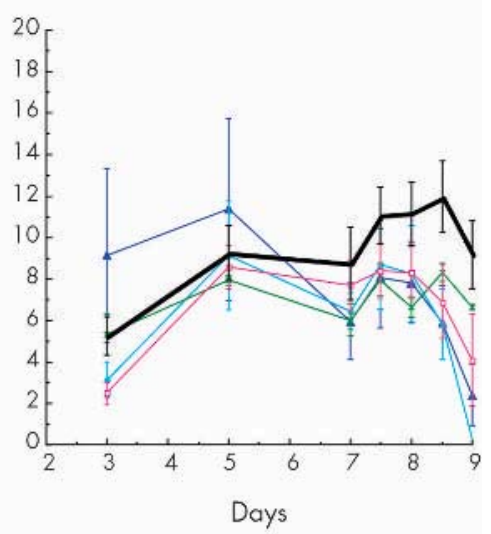

D

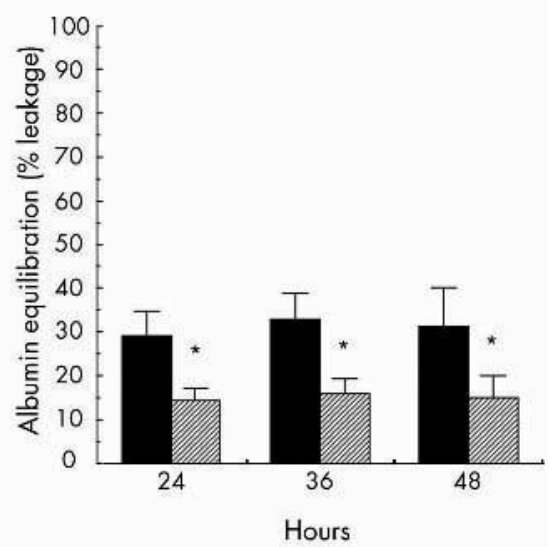

Figure 2 (A) Graph showing transendothelial electrical resistance (TEER) for groups 1-6. TEER of endothelial cells (EC) bathed in conditioned medium from mixed retinal pigmented epithelium (RPE) and Müller cells (dashed line with square icons) is significantly increased compared with control EC (thick line) and other conditioned medium groups. (B) Detail of graph 2A showing control EC (group 6) and conditioned medium groups (groups 2-5). (C) Graph showing inulin equilibration for control EC (group 6) and EC bathed in conditioned medium from mixed RPE and Müller cells (group 1). Note significantly decreased inulin leakage at all time points ( $\left.{ }^{*} p<0.05\right)$. (D) Graph showing albumin equilibration as above for control EC and EC bathed in conditioned medium from mixed RPE and Müller cell cultures. Note significantly decreased albumin leakage at all time points $\left({ }^{*} p<0.05\right)$.

Various theories about the mechanism(s) of retinal laser therapy have been proposed. ${ }^{24}{ }^{25}$ The therapeutic benefit of retinal laser appears to be an indirect effect related to a secondary tissue response, rather than to the immediate burn. ${ }^{6}$ Incompetent retinal vessels regain potency when the outer blood-retinal barrier is repaired after laser therapy. ${ }^{4}$ These observations suggest that the laser scar that forms after photocoagulation may be a source of factors that restore leaking retinal vessels. RPE and Müller cells react to tissue destruction by assembling at the site in the immediate and early phases, suggesting that they play an important role in repair of the outer blood-retinal barrier. ${ }^{26}$ Although the response of RPE cells to injury appears to be rapid, that of the Müller cells is temporarily delayed. Patterns of growth factor expression following photocoagulation in normal pig retinas have been studied to understand how RPE and Müller cells might play a contributory role in retinal wound healing. ${ }^{27}$ RPE may orchestrate the initial response(s) via TGF- $\beta$ which is a chemoattractant for inflammatory cells and promotes matrix deposition-as well as PDGF, EGF, TGF- $\alpha$, and FGFto promote the proliferation of RPE and other cells.
Thereafter the reparative effects appear to be mediated by a combination of autocrine and paracrine signals from the major cell types, including RPE and Müller cells. ${ }^{27}$

We used long term cell cultures to control for artefacts that might be mistaken for a "laser induced" response, as we have previously found that short term cultured cells appear to have an activated phenotype (unpublished). Other in vitro studies have used short term RPE cultures to investigate the effect of conditioned medium on EC proliferation. ${ }^{28}{ }^{29}$ We believe that our study is the first to investigate the effect of diffusible substances from RPE cells on EC permeability. The short versus long term (present study) culture conditions and variations in cell confluency may elicit different factors from RPE. Endothelial cell responses to RPE grown under different culture conditions are likely to be variable.

Inulin is a low molecular weight molecule (MW 50005500). Its leakage across EC monolayers reflects TEER and is an accepted measure of paracellular permeability. ${ }^{30}$ In the present study, the larger albumin molecule (MW 69 000) was more successfully retarded by the EC barrier (see fig 2C and D). We have observed that in vitro EC may grow unreliably, 
forming multilayers that do not always achieve complete barrier formation. ${ }^{20}$ Nevertheless, the significant degree to which conditioned medium from the mixed RPE and Müller cells contributed to decreased permeability of the above mentioned macromolecules, provides further evidence of the in vitro plasticity of the RCEC monolayer.

It is well established that the scar formed after laser therapy is comprised predominately of RPE and Müller cells. In this study we found that only the supernatants from mixed RPE and Müller cells significantly decreased leakage for three measures of EC monolayer permeability. These results support the suggestion that a secretory product(s) from the laser induced scar may contribute to tightening leaky retinal blood vessels. Further work is necessary to identify factor(s) that may contribute to the barrier tightening effect.

\section{ACKNOWLEDGEMENTS}

We acknowledge the Heart Research Institute, Sydney, Australia for use of the liquid scintillation beta counter. We thank Dr Kai Lo for statistical advice, Dr Li Wen for advice regarding RPE isolation, Diana van Driel for assistance with images, and Dr Goff Quinn for helpful discussions. MCM is funded by the Sydney Foundation for Medical Research. This work was supported by Diabetes Australia (MCG).

\section{Authors' affiliations}

M Tretiach, M C Madigan, M C Gillies, Save Sight Institute, Department of Clinical Ophthalmology, University of Sydney, Sydney, Australia

\section{REFERENCES}

1 Ferris FL 3rd, Patz A. Macular edema. A complication of diabetic retinopathy. Surv Ophthalmol 1984;28(Suppl):452-61.

2 Aiello LM. Perspectives on diabetic retinopathy. Am J Ophthalmol 2003; 136:122-35.

3 Pollack A, Korte GE. Repair of retinal pigment epithelium and choriocapillaries after laser photocoagulation: correlations between scanning electron, transmission electron and light microscopy. Ophthalmic Res 1997;29:393-404.

4 Roider J, Michaud NA, Flotte TJ, et al. Response of the retinal pigment epithelium to selective photocoagulation. Arch Ophthalmol 1992;110:1786-92

5 Wallow IH. Repair of the pigment epithelial barrier following photocoagulation. Arch Ophthalmol 1984;102:126-35.

6 Marshall J, Clover G, Rothery S. 1.3 Some new findings on retinal irradiation by krypton and argon lasers. In: Birngruber R, Gabel V-P, eds. Documenta Ophthalmologica Proceedings Series 36. The Hague: Dr W Junk Publishers, 1984:21-37.

7 Marshall J. Interactions between sensory cells, glial cells and the retinal pigment epithelium and their response to photocoagulation. Dev Ophthalmol 1981;2:308-17

8 Del Priore LV, Glaser BM, Quigley HA, et al. Response of pig retinal pigment epithelium to laser photocoagulation in organ culture. Arch Ophthalmol 1989; 107:119-22.
9 Smiddy WE, Fine SL, Quigley HA, et al. Cell proliferation after laser photocoagulation in primate retina. An autoradiographic study. Arch Ophthalmol 1986;104:1065-9

10 Johnson NF, McNaught El, Foulds WS. Effect of photocoagulation on the barrier function of the pigment epithelium. II. A study by electron microscopy. Trans Ophthalmol Soc UK 1977;97:640-51.

11 Humphrey MF, Chu Y, Mann K, et al. Retinal GFAP and bFGF expression after multiple argon laser photocoagulation injuries assessed by both immunoreactivity and mRNA levels. Exp Eye Res 1997:64:361-9.

12 Edwards RB. Culture of mammalian retinal pigment epithelium and neural retina. Methods Enzymol 1982;81:39-43.

13 Winkler J, Hagelstein S, Rohde $M$, et al. Cellular and cytoskeletal dynamics within organ cultures of porcine neuroretina. Exp Eye Res 2002;74:777-88.

14 Smith ME. Phagocytic properties of microglia in vitro: implications for a role in multiple sclerosis and EAE. Microsc Res Tech 2001;54:81-94.

15 Roque RS, Caldwell RB, Behzadian MA. Cultured Muller cells have high levels of epidermal growth factor receptors. Invest Ophthalmol Vis Sci 1992:33:2587-95.

16 Hicks D, Courtois Y. The growth and behaviour of rat retinal Muller cells in vitro. 1. An improved method for isolation and culture. Exp Eye Res 1990;51:119-29.

17 Burke JM, Foster SJ. Culture of adult rabbit retinal glial cells: methods and cellular origin of explant outgrowth. Curr Eye Res 1984;3:1169-78.

18 Kaida M, Cao F, Skumatz CM, et al. Time at confluence for human RPE cells: effects on the adherens junction and in vitro wound closure. Invest Ophthalmol Vis Sci 2000;41:3215-24.

19 Gillies MC, Su T. High glucose inhibits retinal capillary pericyte contractility in vitro. Invest Ophthalmol Vis Sci 1993;34:3396-401.

20 Tretiach M, Van Driel D, Gillies M. Transendothelial electrical resistance of bovine retinal capillary endothelial cells is influenced by cell growth patterns: an ultrastructural study. Clin Experiment Ophthalmol 2003;31:348-53.

21 Gillies MC, Su T, Naidoo D. Electrical resistance and macromolecular permeability of retinal capillary endothelial cells in vitro. Curr Eye Res 1995; 14:435-42

22 Brown J, Reading SJ, Jones S, et al. Critical evaluation of ECV304 as a human endothelial cell model defined by genetic analysis and functional responses: a comparison with the human bladder cancer derived epithelial cell line T24/ 83. Lab lnvest 2000;80:37-45.

23 Penfold PL, Wen L, Madigan MC, et al. Triamcinolone acetonide modulates permeability and intercellular adhesion molecule-1 (ICAM-1) expression of the ECV304 cell line: implications for macular degeneration. Clin Exp Immunol 2000;121:458-65.

24 L'Esperance FA Jr. An opthalmic argon laser photocoagulation system: design, construction, and laboratory investigations. Trans Am Ophthalmol Soc 1968;66:827-904.

25 Stefansson $\mathrm{E}$. The therapeutic effects of retinal laser treatment and vitrectomy. A theory based on oxygen and vascular physiology. Acta Ophthalmol Scand 2001;79:435-40

26 Hara S, Sakuraba T, Nakazawa M. Morphological changes of retinal pigment epithelial and glial cells at the site of experimental retinal holes. Graefes Arch Clin Exp Ophthalmol 2000;238:690-5.

27 Xiao M, McLeod D, Cranley J, et al. Growth factor staining patterns in the pig retina following retinal laser photocoagulation. $\mathrm{Br} J$ Ophthalmol 1999;83:728-36.

28 Glaser BM, Campochiaro PA, Davis JL Jr, et al. Retinal pigment epithelial cells release inhibitors of neovascularization. Ophthalmology 1987:94:780-4.

29 Yoshimura N, Matsumoto M, Shimizu H, et al. Photocoagulated human retinal pigment epithelial cells produce an inhibitor of vascular endothelial cell proliferation. Invest Ophthalmol Vis Sci 1995;36:1686-91.

30 Milton SG, Knutson VP. Comparison of the function of the tight junctions of endothelial cells and epithelial cells in regulating the movement of electrolytes and macromolecules across the cell monolayer. J Cell Physiol 1990; 144:498-504. 